\title{
Com podem preveure la caiguda dels arbres a causa del vent?
}

Francisco M. Sánchez Guerrero (fsanch27@xtec.cat) Escola de Port-rodó, Campredó (Baix Ebre).

Un dia la Maria (9 anys) va preguntar: "Mestre, com podem preveure la caiguda dels arbres a causa del vent i la pluja?" Respondre aquesta pregunta ha implicat i compromès a tota l'escola, a la comunitat educativa $i$ al municipi en general. També ha estat un projecte destacat al Portal Xtec i ha aparegut en diferents programes de televisió, de ràdio i a la premsa. La construcció d'una estació meteorològica equipada emprant materials reutilitzats i/o de baix cost, el disseny i l'elaboració d'un mapa de perillositat, que ha incorporat a Campredó al Google Maps, una conferència científica i la participació a la web del meteoròleg, Alfred Rodríguez Picó, són activitats destacades d'aquest projecte.

Paraules clau: Vent, estació meteorològica, pressa de dades, experimentació.

One day Maria (a 9 years old girl) asked: "Teacher, how can we predict tree falling due to wind and rain?" Without planning, this question has involved and engaged the whole school, the educational community and the town. This is an outstanding project at Xtec Portal and has appeared on various television programs, radio and in the newspapers. The weather station construction, equipped using reused and/or low cost materials, the design and development of a danger map, which has incorporated Campredó to Google Maps, a scientific conference and the participation in the Web of the meteorologist, Alfred Rodriguez Picó, are highlights of this project.

Keywords: Wind, weather station, data acquisition experiments.

A les Terres de l'Ebre quan bufa el Mestral (vent del nord-est) ho fa amb força, i al petit poble de Campredó, ho fa amb més intensitat. Un dia, la Maria va fer una pregunta: Mestre:

"Com podem preveure la caiguda del arbres a causa del vent?"

Aquesta innocent pregunta va portar a desenvolupar un projecte què, a més de comprometre a tota la classe, es va estendre a tota l'escola i va implicar al poble fins al punt d'arribar als mitjans de comunicació comarcals. Com podem preveure la caiguda dels arbres a causa del vent?

Començar sembla fàcil, només cal mesurar el vent però, Port-rodó és una escola rural amb mitjans limitats, era necessari utilitzar materials de mesura senzills i econòmics

\section{MUNTEM UNA ESTACIÓ METEOROLÒ- GICA DE BAIX COST.}

Vam construir un pluviòmetre que ens va servir, a més de per mesurar la quantitat de pluja, per treballar les proporcions. Amb dos termòmetres iguals vam muntar un psicròmetre. Prèviament havíem experimentat amb la dilatació amb un pot d'alcohol tenyit de vermell (figura 2). Vam acoblar un penell sobre un eix de persiana, amb ell, vam aprendre els noms dels vents. Amb un motor d'ordinador un parell de CDs, tres topes de porta i un velocímetre de bicicleta vam construir un anemòmetre. En desmuntar l'ordinador, vam aprofitar per estudiar els seus components. Finalment, per construir un baròmetre, després d'experimentar sobre la pressió atmosfèrica i, de retruc, sobre la tensió superficial de l'aigua, tan sols vam necessitar un globus, un pot de vidre i un palet per intensificar la vibració de la membrana del globus. 


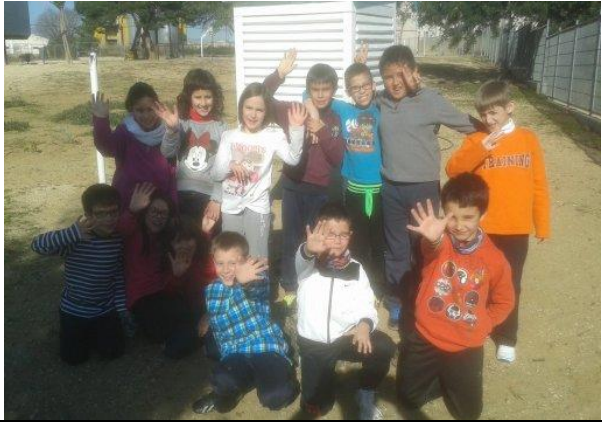

Figura 1. Els protagonistes: l'alumnat de cicle mitja.

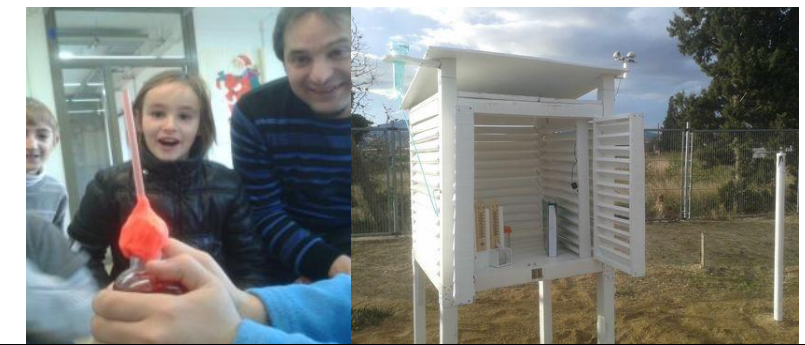

Figures 2 i 3. Experimentant amb la dilatació i l'estació meteorològica.

Amb motiu del dia mundial de la ciència, l'Observatori de l'Ebre va fer un dia de portes obertes, Alguns alumnes van poder assistir i van poder observar i preguntar com és i quines característiques té una gàbia meteorològica. Una empresa de muntatge de palets ens va regalar tota la fusta que vam necessitar, i tots els nens de l'escola des de tercer fins sisè, a les hores de pati i de manera totalment voluntària, van ajudar a pintar-la. Ara ja podíem mesurar diverses variables meteorològiques: direcció i intensitat del vent, pluja, pressió atmosfèrica, temperatura i, gràcies a unes taules penjades a la classe, també podríem recollir dades sobre la humitat i la sensació tèrmica.

Però la nostra tasca no va ser únicament prendre dades, sinó també fer gràfiques d'evolució i introduir-les al web més visitat de Catalunya: www.pico.cat. El mateix Alfred Rodríquez Picó, al canal PicóTV, ens va felicitar públicament per tot el treball pedagògic i científic que anàvem fent.

\section{DE CAMPREDÓ A TOT EL MÓN.}

Una vegada construïda i en marxa la nostra estació meteorològica, va sorgir una altra pregunta: Quan es pot considerar que el vent és fort? Per poder contestar-la, ens ajudem de les noves tecnologies. Vam consultar els diaris locals i vam recollir un munt de dades fins arribar a la conclusió que un arbre pot tombar-se en un dia de pluja amb vents sostinguts de $60 \mathrm{~km} / \mathrm{h}$.

Què podem fer $\mathrm{amb}$ tota aquesta informació que tenim ara per millorar el nostre poble? Aquesta pregunta, plantejada als alumnes, va ser contestada en poc més de cinc minuts: fer un mapa de perillositat.

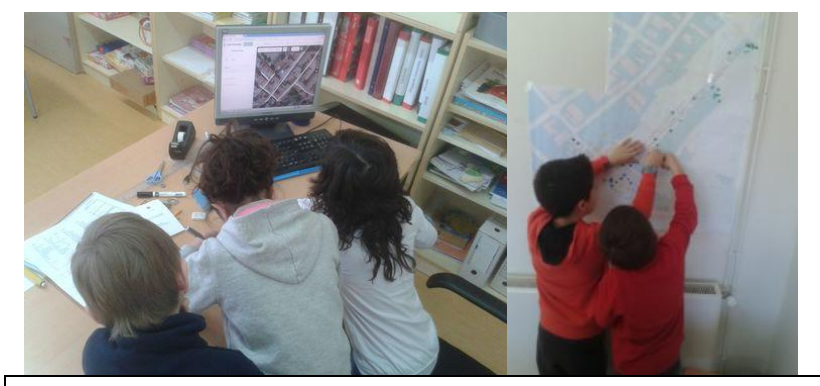

Figures 4 i 5 . Gràcies al projecte, fem que Campredó sigui a Google Maps i muntem el mapa de zones verdes.

El primer problema era que no existia cap mapa del poble, ni tan sols en Google Maps, per tant, es va decidir fer-ho amb el programari lliure: OpenStreetMap. Vam dividir el poble en seccions, i cada grup d'alumnes es va encarregar d'anotar els noms dels carrers, serveis i comerços segons la parcel.la li va ser assignada. A mesura que teníem la informació, s'anava introduint a l'ordinador per poder confeccionar el mapa del poble. Gràcies a aquesta iniciativa, ara tothom pot accedir al mapa detallat de Campredó, no només amb l'OpenStreetMap sinó també pel Google Maps.

Ara ja teníem el mapa del poble, era el moment de buscar elements susceptibles de caure a causa del vent, indicaríem així els potencials perills. Vam fotografiar tots els arbres que hi ha al poble i vam fer les icones corresponents (dibuixant les fulles). Tota aquesta informació la vam incloure en un PDF interactiu on amb un sol clic es podia accedir a la foto de l'arbre, o a un indicador amb els colors del semàfor segons el grau de perillositat.

Ja disposavem d'una estació meteorològica per prendre dades del temps i d'un mapa de perillositat amb el que de retruc hem situat Campredó a Internet, era el moment de pensar com treure profit del vent. 


\section{COM ES POT APROFITAR LA FORÇA DEL VENT?}

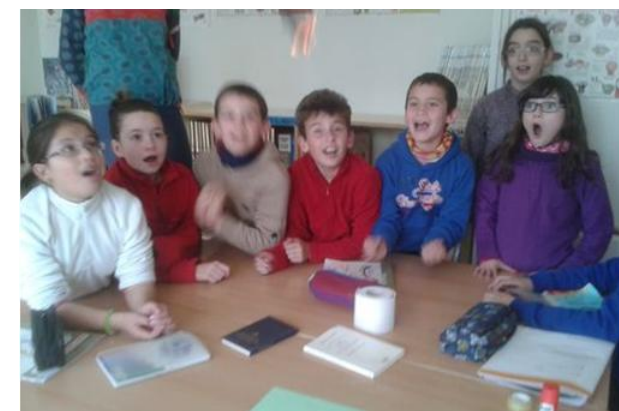

Figura 6. L'aire calent puja.

Els alumnes van pensar en tres possibilitats: generar electricitat, inflar globus i refredar la biblioteca

Observant que un ventilador funciona gràcies a l'electricitat (moviment d'una bobina de coure dins d'un camp magnètic) vam pensar que si fèiem moure les aspes, potser l'efecte seria el contrari, és a dir, en generaria electricitat. Ho vam experimentar amb un cooler (ventilador d'ordinador) i vam aconseguir, gràcies al vent, un corrent de $2 \mathrm{~V}$ d'electricitat, suficient per carregar una petita bateria.

Per demostrar que el vent pot inflar globus, vam fer servir un molí de vent que movia una manxa i condensava l'aire dins d'una ampolla, vam construir un coet d'aigua que, gràcies únicament a la pressió de l'aire emmagatzemat a l'ampolla es va enlairar prop de 20 metres.

La biblioteca de l'escola està molt il.luminada, té llum solar durant tot el dia, i això fa que també augmenti la temperatura a l'interior. Amb el que vam aprendre mitjançant un petit experiment on vam poder observar que l'aire calent puja, i gràcies a una sèrie de ventiladors moguts pel vent, vam dissenyar un model per aconseguir disminuir la temperatura de la biblioteca. Però tot això que fem a l'escola ho ha de saber tothom!

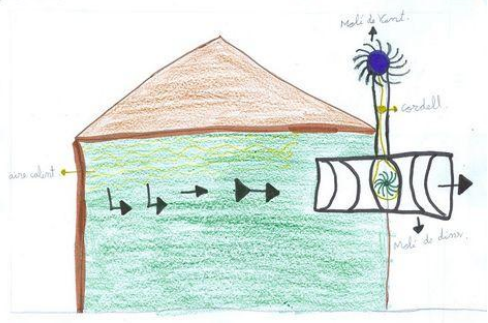

Figura 7. Dissenyem com refredar la biblioteca.

\section{QUE TOTHOM HO SÀPIGA!}

Els resultats de la nostra feina s'han de compartir amb la comunitat. En el nostre cas ho vam fer: al ja esmentat bloc d'Alfred Rodríguez Picó i també a la página web de la Xtec, a més del bloc de l'escola. També vam fer una conferència al Casal del poble on es va aprofitar l'ocasió per fer entrega a l'alcalde dels mapes de perillositat $i$ de zones verdes. En diferents diaris locals, i concretament al diari Més Ebre omplint tota la contraportada. Un reportatge a la televisió local i un altre una mica més curt emès en totes les televisions locals de Catalunya. Així mateix vam fer una entrevista en directe a Ràdio Antena Caro, i finalment una visita al plató de televisió en directe on, no només vam poder explicar el projecte a tota la comarca durant més de 30 minuts, sinó que també els alumnes van poder ensenyar i explicar algun dels experiments que vam fer a classe.

Si voleu saber més sobre aquest projecte, po-
deu l'ARC http://apliense.xtec.cat/arc/node/30053. Aquí es pot descarregar tot el material i guies que expliquen amb tot tipus de detalls per a que qualsevol mestre ho pugui dur a terme amb els seus alumnes.

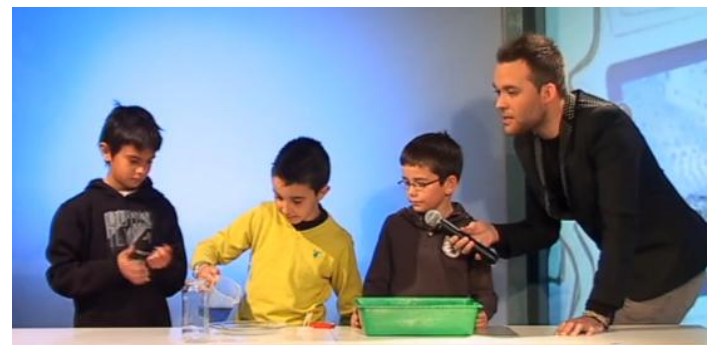

Figura 8. En directe al plató de Canal TE.

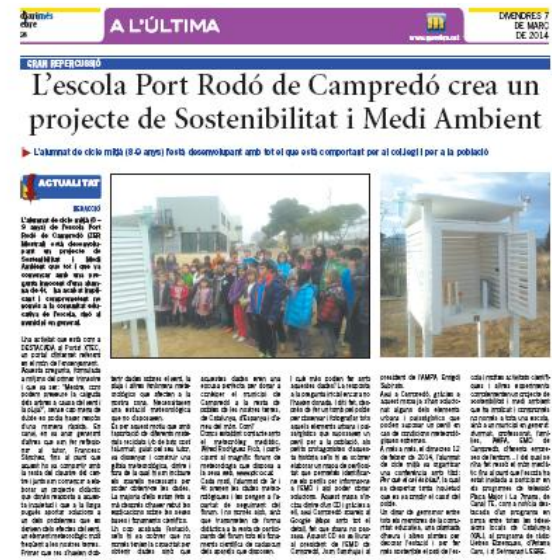

Figura 9. Vam sortir als mitjans de comunicació de tota la comarca. 
Malala Yousafzai, el mateix dia que feia setze anys, davant les Nacions Unides va dir: "Un nen, un mestre, un llibre $i$ un llapis poden canviar el món". Nosaltres, des del nostre petit poble no hem canviat el món, però l'alcalde davant de totes les comarques de les Terres de l'Ebre va dir: "Hi ha un abans i un després d'aquest projecte. Campredó ja no és el mateix".
Quan el vaig sentir, vaig pensar: "El món potser no, però el poble sí que l'hem canviat."

\section{BIBLIOGRAFIA}

OpenStreetMap (España):

http://www.openstreetmap.es/

Canal Terres de l'Ebre, "Plaça Major" 28/02/2014

http://canalte.xiptv.cat/placa-major/capitol/placa-

major-28-02-2014 